\title{
Viscoelastic and fatigue properties of model methacrylate-based dentin adhesives
}

\author{
Viraj Singh ${ }^{1}$, Anil Misra ${ }^{2,3}$, Orestes Marangos ${ }^{2}$, Jonggu Park ${ }^{3}$, Qiang Ye ${ }^{3}$, Sarah L. \\ Kieweg $^{1}$, and Paulette Spencer ${ }^{1,3}$ \\ ${ }^{1}$ Mechanical Engineering Department, University of Kansas, Lawrence, Kansas 66045-7609 \\ ${ }^{2}$ Civil, Environmental and Architectural Engineering Department, University of Kansas, Lawrence, \\ Kansas 66045-7609 \\ ${ }^{3}$ Bioengineering Research Center (BERC), University of Kansas, Lawrence, Kansas 66045-7609
}

\begin{abstract}
The objective of the current study is to characterize the viscoelastic and fatigue properties of model methacrylate-based dentin adhesives under dry and wet conditions. Static, creep, and fatigue tests were performed on cylindrical samples in a 3-point bending clamp. Static results showed that the apparent elastic modulus of the model adhesive varied from 2.56 to $3.53 \mathrm{GPa}$ in the dry condition, and from 1.04 to $1.62 \mathrm{GPa}$ in the wet condition, depending upon the rate of loading. Significant differences were also found for the creep behavior of the model adhesive under dry and wet conditions. A linear viscoelastic model was developed by fitting the adhesive creep behavior. The developed model with 5 Kelvin Voigt elements predicted the apparent elastic moduli measured in the static tests. The model was then utilized to interpret the fatigue test results. It was found that the failure under cyclic loading can be due to creep or fatigue, which has implications for the failure criterion that are applied for these types of tests. Finally, it was found that the adhesive samples tested under dry conditions were more durable than those tested under wet conditions.
\end{abstract}

\section{Keywords}

dentin adhesive; fatigue; creep; viscoelastic; dry and wet; S-N curves; prony series

\section{INTRODUCTION}

In 2005166 million dental restorations were placed in the United States ${ }^{1}$ and clinical studies suggest that more than half were replacements for failed restorations. ${ }^{2}$ Replacements of failed restorations accounts for nearly $70 \%$ of all restorative dentistry ${ }^{2}$ and this emphasis on replacement therapy is expected to grow as the public's concern about mercury release from dental amalgam forces dentists to select alternative materials. Resin composite is the most commonly used alternative, ${ }^{3}$ but moderate to large composite restorations have higher failure rates, more recurrent caries, and increased frequency of replacement as compared with amalgam. ${ }^{2-8}$ The primary factor in the premature failure of moderate to large composite restorations is recurrent decay at the margins of the restorations. ${ }^{7}$

(C) 2010 Wiley Periodicals, Inc.

Correspondence to: A. Misra; amisra@ku.edu. 
The composite is too viscous to bond directly to the tooth, thus a low viscosity adhesive is used to form a connection between the tooth and composite. The tooth surface is generally prepared by pretreatment with acids such as $35 \%$ phosphoric acid. The adhesive infiltrates the porosities created in the tooth by the acid etchant. Acid-etching provides effective mechanical bonding between enamel and adhesive, but bonding to dentin has been fraught with problems. Clinicians frequently find very little enamel available for bonding at the gingival margin of class II composite restorations and thus, the bond at this margin depends on the integrity of the adhesive seal formed with dentin. ${ }^{9,10}$ At the vulnerable gingival margin, the dentin adhesive is the primary barrier between the prepared tooth and surrounding environment. A failed adhesive means that there are gaps between the tooth and composite. Bacterial enzymes, oral fluids and bacteria can infiltrate these gaps and this activity will lead to recurrent decay, hypersensitivity, pulpal inflammation, and restoration failure. ${ }^{2,11-14}$ The lack of effective and durable dentin adhesives is generally considered one of the major problems with the use of composites in direct restorative dentistry.

In the mouth, dentin adhesives are subjected to both chemical and mechanical stresses. The interplay of these stresses can lead to a change in the mechanical properties of the adhesive. The mechanical property change results from a variety of mechanisms including (1) proliferation of surface and subsurface flaws due to the combined effects of mechanicalloads and exposure to chemical challenges and (2) change in the chemical nature of the polymer in the form of either crystallization or plasticization. Our previous work has shown that the mechanical property of the adhesive not only effects the overall bond or shear strength but has a profound influence on the load transfer mechanism at the dentin-adhesive (a/d) interface. ${ }^{15,16}$ Therefore the change in the mechanical property of the adhesive with time can result in a gradual loss of the mechanical integrity of the $a / d$ interface.

To understand the mechanical behavior of the adhesive under stress that simulates cyclic oral loading requires characterization of the viscoelastic and fatigue properties of the material. These dentin adhesive properties have not been widely investigated. Most dentin adhesive characterization studies are focused on bond strength investigations that by nature incorporate the effects of dentin and composite. ${ }^{17-19}$ The objective of this article is to characterize the viscoelastic and fatigue properties of model methacrylate-based dentin adhesives under both dry and wet (submerged in water) conditions. The measured mechanical properties are incorporated in a linear viscoelastic model to show the effect of these properties on the overall fatigue failure behavior of the adhesive.

\section{MATERIALS AND METHODS}

\section{Material}

The model adhesives consisted of 2-Hydroxyethylmethacrylate (HEMA, Acros Organics, NJ) and 2,2-bis[4-(2-hydroxy-3-methacryloxypropoxy) phenyl]-propane (BisGMA, Polysciences, Warrington, PA) with a mass ratio of 45/55 (HEMA/BisGMA). The following photoinitiators (all from Aldrich, Milwaukee, WI) were used in the study: camphorquinone (CQ), ethyl-4-(dimethylamino) benzoate (EDMAB) and diphenyliodonium hexafluorophosphate (DPIHP). The amounts of photosensitizer, coinitiator amine and iodonium salt were fixed at 0.5 mass $\%$ with respect to the total amount of monomer. Continuous shaking and sonication for $48 \mathrm{~h}$ were required to yield well-mixed resin solutions. All the materials in this study were used as received.

\section{Sample Preparation}

Circular beam specimens of diameter $1 \mathrm{~mm}$ and length $15 \mathrm{~mm}$ were made by curing the resin in a glass-tubing mold (Fiber Optic Center Inc, \#CV1012, Vitrocom Round Capillary 
Tubing of Borosilicate Glass). The model adhesives were injected into the tubing using a micro-pipette and light polymerized with a LED light curing unit of intensity $250 \mathrm{~mW} / \mathrm{cm}^{2}$ and area $6.25 \mathrm{~mm}^{2}$ for $9 \mathrm{~s}$ (LED Curebox, Proto-tech, and Portland, OR). The polymerized samples were stored in dark at room temperature for two days to provide adequate time for post-cure polymerization. The samples were then extracted from the glass tubing mold and stored for three days in a vacuum oven in the presence of a drying agent at $37^{\circ} \mathrm{C}$ to remove water that may have been absorbed during specimen preparation. The specimens used for wet testing were submerged in distilled water for at least five days at $37^{\circ} \mathrm{C}$ prior to mechanical testing. For the wet condition, mechanical testing was performed with the specimens submerged in water.

\section{Degree of conversion}

The degree of conversion (DC) was determined using Raman spectroscopy. Spectra were collected using a Lab-RAM ARAMIS Raman spectrometer (LabRAM HORIBA Jobin Yvon, Edison, NJ) with a HeNe laser $(\lambda=633 \mathrm{~nm}$, a laser power of $17 \mathrm{~mW})$ as an excitation source. To determine the DC, spectra of the uncured resins and beam specimens were acquired over a spectral range of $700-1800 \mathrm{~cm}^{-1}$. The change of the band height ratios of the aliphatic carbon-carbon double bond $(\mathrm{C}=\mathrm{C})$ peak at $1640 \mathrm{~cm}^{-1}$ and the aromatic $\mathrm{C}=\mathrm{C}$ at $1610 \mathrm{~cm}^{-1}$ (phenyl) in both the cured and uncured states was monitored. ${ }^{20} \mathrm{DC}$ was calculated using the following formula based on the decrease in the intensity band ratios before and after light curing:

$$
\mathrm{DC}(\%)=100\left[1-\left(R_{\text {cured }} / R_{\text {uncured }}\right)\right], R=\left(\text { band height at } 1640 \mathrm{~cm}^{-1} / \text { band height at } 1610 \mathrm{~cm}^{-1}\right)
$$

The average value of DC was obtained from three readings acquired from different positions on the sample.

\section{Mechanical tests}

Instrument-Dynamic Mechanical Analyzer (DMAQ800. TA Instruments, New Castle, USA) was used in a $10 \mathrm{~mm} 3$-point bending configuration for all the mechanical testing. For wet testing, a submersion clamp was used and the adhesive samples were submerged in water during the test. Temperature was kept at $37^{\circ} \mathrm{C}$ for all the tests.

Static-Static or monotonic tests were performed on dentin adhesives in both dry and wet conditions to obtain the stress-strain curves. During the static tests, load was increased at a constant rate until the sample ruptured. These tests were performed at three different loading rates of $10 \mathrm{~N} / \mathrm{min}, 0.1 \mathrm{~N} / \mathrm{min}$, and $0.0075 \mathrm{~N} / \mathrm{min}$. Three specimens were tested for $10 \mathrm{~N} / \mathrm{min}$ and $0.1 \mathrm{~N} / \mathrm{min}$ loading rates, while two specimens were tested for $0.0075 \mathrm{~N} / \mathrm{min}$ loading rate. The highest loading rate was determined from the machine limits, while the lowest loading rate was based on the time needed for the completion of a test. The intermediate loading rate was chosen arbitrarily.

Creep-Creep testing is performed by applying a constant stress over time. The creep test was performed at four different stress-levels (80 MPa, $55 \mathrm{MPa}, 48.8 \mathrm{MPa}$, and $30.5 \mathrm{MPa}$ ) and (30.5 MPa, 24.4 MPa, 18.8 MPa, and 12.2 MPa) for the dry and wet conditions, respectively. These stress levels correspond to the mean stress-levels of fatigue tests and were chosen to study the linear to nonlinear transition of the dentin adhesive behavior.

For the creep test, the sample was placed on the 3-point clamp and a preload of $0.01 \mathrm{~N}$ was applied so that the sample is clamped in the test fixture. Subsequently, a constant stress was applied for $120 \mathrm{~min}$. The stress was then removed and the sample was allowed to recover for 
$30 \mathrm{~min}$. Most of the samples returned to their original state in $30 \mathrm{~min}$. Strain was measured throughout the process.

Fatigue-A material can fail at a stress below its ultimate strength because of damage accumulation during cyclic loading. This phenomenon is called fatigue failure. Fatigue tests can be done using either a stress-based or strain-based approach. In this work, stress based approach was used for both the dry and wet dentin adhesives. The cyclic stress applied during a fatigue test is depicted in Figure 1.

All the fatigue tests were done at a stress ratio $R$ of 0.1 since it gives a broad range of stress amplitudes and allows for testing at low mean stress. In this case, the mean stress and stress amplitude are related as follows: $\sigma_{\text {mean }}=\frac{11}{9} \sigma_{a}$ while the maximum stress is given by $\sigma_{\max }=\frac{20}{9} \sigma_{a}$. All of the fatigue tests were performed at $5 \mathrm{~Hz}$.

Stress amplitudes for fatigue testing were based upon the stress-strain curves obtained from the static tests. Stress amplitudes were selected so that the maximum stress over a cycle during the fatigue loading was smaller than the yield stress. This approach avoided any permanent deformation to the specimen. The stress amplitudes and mean stresses for the dry tests were 45, 40, 35, and $30 \mathrm{MPa}$ and 55, 48.8, 42.7, and 36.6 MPa, respectively. The stress amplitudes and mean stresses for the wet tests were 25, 20, 15 and $10 \mathrm{MPa}$, and 30.5, 24.4, 18.8 , and $12.2 \mathrm{MPa}$, respectively.

Viscoelastic model for dentin adhesive-To model the mechanical behavior of the dentin adhesive, five Kelvin-Voigt elements with different retardation times were used to form a Prony series. ${ }^{21}$ The creep compliance function with five Kelvin-Voigt elements connected in series is given by the equation

$$
J(t)=J_{0}+J_{1}\left(1-e^{-\frac{t}{\tau_{1}}}\right)+J_{2}\left(1-e^{-\frac{t}{\tau_{2}}}\right)+J_{3}\left(1-e^{-\frac{t}{\tau_{3}}}\right)+J_{4}\left(1-e^{-\frac{t}{\tau_{4}}}\right)+J_{5}\left(1-e^{-\frac{t}{\tau_{5}}}\right)
$$

Here $J_{0}, J_{1}, J_{2}, J_{3}, J_{4}$, and $J_{5}$ are creep constants and $\tau_{1}, \tau_{2}, \tau_{3}, \tau_{4}, \tau_{5}$ are the retardation times associated with each Kelvin-Voigt element. Using the creep compliance function, the creep constitutive equation is written as:

$$
\varepsilon(t)=J(t) \sigma(0)+\int_{0}^{t} J(t-s) \frac{d \sigma(t)}{d t} d s
$$

where $\sigma(0)$ is the stress at the time zero. In a creep test constant stress is applied, therefore, $\frac{d \sigma(t)}{d t}=0$, while in a static test stress is applied at a constant rate, that is $\frac{d \sigma(t)}{d t}=k$.

\section{RESULTS \\ Degree of conversion}

Twelve randomly selected specimens were tested for degree of conversion after five days from the day sample preparation. The measured mean degree of conversion was $91.44 \%$ (0.816). Typically for these types of samples the initial degree of conversion is $8-10 \%$ lower than the final degree of conversion at five days.

\section{Static tests}

Figures 2 and 3 provide the stress-strain curves obtained from the static tests. As seen from these figures, the loading rate has a large effect on the stress-strain behavior of dentin adhesives in both dry and wet conditions. As expected, the slopes of the linear part of the 
stress-strain curves, defined as the apparent "elastic" modulus, are significantly different for the three loading rates. At a loading rate of $0.1 \mathrm{~N} / \mathrm{min}$ and under wet conditions, the dentin adhesives have an elastic modulus of $\sim 1.46 \mathrm{GPa}$, but the same material at a similar loading rate under dry conditions has an elastic modulus $\sim 3.06 \mathrm{GPa}$. Similarly, at a loading rate of $10 \mathrm{~N} / \mathrm{min}$ the flexural strength decreases from $\sim 160 \mathrm{MPa}$ under dry conditions to $\sim 60 \mathrm{MPa}$ in the wet case.

\section{Creep}

Figures 4 and 5 show the results of the creep tests. For each stress-level two samples were tested. The results from two samples were within the five percent. While the creep behavior for the lower three stress-levels appears linear, the creep behavior at the highest stress-level is nonlinear. For material to have linear creep behavior at different stress levels, strain ratio at any time should be equal to the stress ratio. In Figure 4, strain at $55 \mathrm{MPa}$ is $\sim 1.8$ times the strain at $30.5 \mathrm{MPa}$ at any time, which is equal to the corresponding stress ratio. This is not true for the $80 \mathrm{MPa}$ stress-level. In this case the strain ratio is not the same as the corresponding stress ratio over the duration of the test. Similarly in Figure 5, using the same analysis as for the dry specimens, we can see that creep curves for the lower three amplitudes are approximately linear whereas $30.5 \mathrm{MPa}$ falls in the nonlinear range.

The creep behavior shown in Figures 4 and 5 is modeled by fitting the data to the Prony series given in Eq. (1). This Prony series consists of six coefficients and five retardation times that need to be determined. To evaluate the constants, linear creep curves $30.5,48.8$, and $55 \mathrm{MPa}$ in dry case and $12.2,18.8$, and 24.4 in wet case were normalized with respect to applied stress and averaged to give one creep compliance curve for wet and dry conditions as shown in Figures 6 and 7. The five element Kelvin-Voigt model was required in order to obtain a good fit over the test duration. Nonlinear least-square subroutine from Mat-lab $2006 \mathrm{~b}$ was used to perform the model fit. The calculated Prony series parameters are shown in Table I along with $R^{2}$ goodness of fit for both wet and dry conditions. While performing least-square fitting care was taken so that the creep constants are nonnegative ${ }^{22,23}$ as they can result in a decrease in strain with time even when constant stress is maintained. There are many methods to avoid non-negative coefficients while fitting creep data, such as interactive adjustment of relaxation or retardation times, ${ }^{24}$ recursive algorithm,,${ }^{25}$ and power law presmoothing. ${ }^{26}$ To avoid nonnegative coefficients in our fitting, the parameters were constrained to be positive for the nonlinear least-square optimization.

\section{Evaluation of viscoelastic model}

For the evaluation of the viscoelastic model, Eq. (2) with initial stress $\sigma(0)=0$ and constant stress rate was used to predict the elastic modulus. Table II compares the measured moduli from the experiment with the predicted moduli using our viscoelastic model for the three different loading rates in both dry and wet conditions. Measured moduli are the slope of the linear portion in Figures 2 and 3. Our prediction shows close agreement with the moduli obtained from the measured curves, indicating that the five element Prony series is a reasonable model for the model dentin adhesive.

\section{Fatigue behavior}

Figures 8-11 show the strain versus time curves for all the different stress amplitudes in both dry and wet fatigue tests. Each figure has a measured curve from the experiment and a predicted curve calculated using Eq. (2), where $\sigma(t)=\sigma_{\mathrm{a}} \sin (\omega t), \omega=2 f \pi$ and $f$ is the cyclic frequency. Although several samples were tested, we show the results for only one representative sample whose initial creep compliance was closest to the initial creep compliance of the fitted model. Fatigue tests were performed until the specimens reached 
failure. Stress amplitudes differed for the two conditions because wet dentin adhesive samples have lower flexural strength than dry dentin adhesive samples (Figure 3).

Failure in a fatigue test occurs either (1) when the sample ruptures or (2) when the strain in the sample becomes sufficiently large. Accordingly, our fatigue limit criterion is based upon the two failure modes: (1) when the sample is completely ruptured or (2) when the strain in the sample has reached a specified limit. The value of limiting strain is chosen using the stress-strain curves from the static tests. From the stress-strain curves we can find the strain at which the material leaves the linear region and enters into the plastic state. For the case of dentin adhesives in this study the material enters the plastic state between $2.0 \%$ and $2.5 \%$. Hence to show the effect of strain criteria on number of cycles to failure we have chosen three different strain values $(2.1 \%, 2.2 \%$, and $2.3 \%)$ and have calculated the number of cycles to failure. The results presented in Tables III and IV shows the average number of cycles, $N$, to failure (and their standard deviation) at different stress levels for dry and wet testing conditions. These results are plotted as the so called 'SN' curves in Figure 12.

\section{DISCUSSION}

In this study we have performed monotonic stress-strain, creep, and fatigue experiments on a model adhesive in both dry and wet conditions. This dentin adhesive has different elastic moduli at different loading rates as shown in Table II. The elastic moduli vary from 1.5 to 2 times as the loading rate is changed from slow to fast. Further, based upon the comparison of static test results (Figures 2 and 3 ) the dentin adhesive is substantially softer and weaker in the wet condition.

Significant differences were also found for the creep behavior of the model adhesive under dry and wet conditions. Creep behavior for both wet and dry testing was found to be linear for the lower three stress values. The creep behavior at stress levels of $80 \mathrm{MPa}$ for dry adhesive (Figure 4) and at $30.5 \mathrm{MPa}$ for the wet adhesive (Figure 5) was found to be nonlinear with creep strains reaching up to $7 \%$ at $120 \mathrm{~min}$. For these large stress levels the samples did not recover their original state. The samples exhibited features associated with large residual strain (samples permanently bent) once the applied stress was removed.

The viscoelastic model used in this study is linear, hence for the calculation of the viscoelastic model parameters only linear creep data were used (lower three stress level in both wet and dry conditions). Creep data were fitted using the nonlinear least square method to calculate the creep constants. The linear viscoelastic model consisting of a five element Prony series was found to predict the rate dependent elastic moduli for our dentin adhesive. This model is useful in discriminating the effect of damage in the fatigue experiments.

Fatigue tests were performed at a frequency of $5 \mathrm{~Hz}$, stress ratio of $R=0.1$, and temperature of $37^{\circ} \mathrm{C}$. Although the test frequency is larger than the typical physiological loading frequency, this frequency was chosen so as to accomplish the tests within a reasonable time frame. Similar test frequency has been used for testing dentin and $a / d$ interfaces ${ }^{19,27}$ Strain in fatigue testing is composed of two parts, (1) strain due to creep under the mean stress and (2) strain due to damage accumulation because of cyclic loading. Therefore, the failure of samples can be considered as either creep failure if the sample remains linear viscoelastic till failure or fatigue failure if it deviates from linear viscoelastic behavior. In Figures 8 through 11 , the predicted strain versus time curves give the creep strain under the mean stress since the model is linear viscoelastic (which does not take into account the damage accumulation). At stress amplitude of $30 \mathrm{MPa}$ and under dry conditions (Figure 8) the predicted and measured curves are parallel to each other, indicating that the sample follows a linear viscoelastic behavior over the duration of the test. The test was stopped at 1400 mins since 
the sample had exceeded the upper strain failure criterion of $2.3 \%$. In this case the sample experienced creep failure, with negligible contribution from damage accumulation. For stress amplitude of $45 \mathrm{MPa}$ in dry testing (Figure 9), the predicted curve was close to the experimental curve in the early part of the loading $(0-5 \mathrm{~min})$, but as time proceeds the measured curve deviates considerably from the predicted curve until the sample failed by rupture at $\sim 23 \mathrm{~min}$. This deviation is caused by damage accumulation that occurs as a result of cyclic loading at higher stress amplitude. For adhesive specimens tested under wet conditions and $25 \mathrm{MPa}$ stress amplitude, large damage accumulation occurred at $10 \mathrm{~min}$. In comparison, at $15 \mathrm{MPa}$ stress amplitude specimens tested under wet conditions accumulated very little damage even at $400 \mathrm{~min}$ (Figure 10).

For the calculation of fatigue life at particular stress amplitude, we chose two different criteria for failure in fatigue. At a failure strain of $2.1 \%$ and stress amplitude of $45 \mathrm{MPa}$, the adhesive tested under dry conditions will last for an average of $1679 \pm 402$ cycles (Table IV). In comparison, at $30 \mathrm{MPa}$ the adhesive specimen will last for an average of $67043 \pm$ 54877 cycles. For all strain criteria the standard deviation becomes larger with a decrease in stress amplitude, that is, there is a large variation in the fatigue life of adhesive specimens at smaller stress amplitudes. This is not unexpected, since sample variability due to surface and sub-surface defects has a larger effect on deformation and failure when the loading amplitude is lower. Finally, we see that the dentin adhesive fatigue-life in wet conditions is considerably smaller than that under dry conditions (Figure 13). Plasticization of polymers due to water is well-known ${ }^{28}$ and the model dentin adhesive studied in this paper appear to suffer greatly from this phenomenon. The large difference in mechanical properties and fatigue behavior under wet conditions could have an adverse impact on adhesive durability in the mouth. In the current study, only one dentin adhesive system composed of two widely used monomers was tested. In comparison, clinical adhesives may be composed of other monomers. These clinical systems are expected to have similar viscoelastic and fatigue behavior although the quantitative results may be different. Similarly the degree of conversion will have effect on quantitative results but the overall behavior of the adhesive system should remain the same.

\section{SUMMARY AND CONCLUSIONS}

Static, creep, and fatigue tests were performed for a model dentin adhesive. Adhesive elastic modulus depends upon the rate of loading. Second, strength and elastic modulus of model dentin adhesives are reduced by nearly one-half when tested under wet conditions. This difference is likely due to the plasticizing effect of water. The viscoelastic model was able to predict the rate-dependent apparent "elastic" modulus. The creep tests and the viscoelastic model showed that the model dentin adhesive is a complex viscoelastic material. Hence, static and creep tests must be performed to characterize the viscoelastic properties of dentin adhesives. We also find that fatigue limit criterion for such polymeric materials should be based upon the two failure modes: (1) when the sample breaks (2) or when the strain in the sample has reached a specified limit. Fatigue tests showed that the model methacrylatebased dentin adhesive tested under dry conditions was more durable than the wet adhesive under constant stress cyclic loading.

\section{Acknowledgments}

Contract grant sponsor: National Institutes of Health/National Institute of Dental and Craniofacial Research; contract grant numbers: R01DE014392-08, 3R01DE014392-08S1 


\section{References}

1. Beazoglou T, Eklund S, Heffley D, Meiers J, Brown LJ, Bailit H. Economic impact of regulating the use of amalgam restorations. Public Health Rep. 2007; 122:657-663. [PubMed: 17877313]

2. Murray PE, Windsor LJ, Smyth TW, Hafez AA, Cox CF. Analysis of pulpal reactions to restorative procedures, materials, pulp capping, and future therapies. Crit Rev Oral Biol Med. 2002; 13:509_ 520. [PubMed: 12499243]

3. Simecek JW, Diefenderfer KE, Cohen ME. An evaluation of replacement rates for posterior resinbased composite and amalgam restorations in US Navy and Marine Corps recruits. J Am Dental Assoc. 2009; 140:200-209.

4. Bernardo M, Luis H, Martin MD, Leroux BG, Rue T, Leitao J, DeR-ouen TA. Survival and reasons for failure of amalgam versus composite posterior restorations placed in a randomized clinical trial. J Am Dent Assoc. 2007; 138:775-783. [PubMed: 17545266]

5. DeRouen TA, Martin MD, Leroux BG, Townes BD, Woods JS, Leitao J, Castro-Caldas A, Luis H, Bernardo M, Rosenbaum G, Martins IP. Neurobehavioral effects of dental amalgam in children: A randomized clinical trial. JAMA. 2006; 295:1784-1792. [PubMed: 16622140]

6. Levin L, Coval M, Geiger SB. Cross-sectional radiographic survey of amalgam and resin-based composite posterior restorations. Quintessence Int. 2007; 38:511-514. [PubMed: 17625635]

7. Mjor IA, Dahl JE, Moorhead JE. Age of restorations at replacement in permanent teeth in general dental practice. Acta Odontologica Scandinavica. 2000; 58:97-101. [PubMed: 10933556]

8. Soncini JA, Maserejian NN, Trachtenberg F, Tavares M, Hayes C. The longevity of amalgam versus compomer/composite restorations in posterior primary and permanent teeth-Findings from the new England children's amalgam trial. J Am Dental Assoc. 2007; 138:763-772.

9. Kleverlaan CJ, Feilzer AJ. Polymerization shrinkage and contraction stress of dental resin composites. Dent Mater. 2005; 21:1150-1157. [PubMed: 16040118]

10. Roulet JF. Benefits and disadvantages of tooth-coloured alternatives to amalgam. J Dent. 1997; 25:459-473. [PubMed: 9604577]

11. Andersson-Wenckert IE, van Dijken JWV, Kieri C. Durability of extensive Class 11 opensandwich restorations with a resin-modified glass ionomer cement after 6 years. Am J Dentistry. 2004; 17:43-50.

12. Brannstrom M. Communication between the oral cavity and the dental-pulp associated with restorative treatment. Operat Dent. 1984; 9:57-68.

13. Hashimoto M, Ohno H, Kaga M, Endo K, Sano H, Oguchi H. Resin-tooth adhesive interfaces after long-term function. Am J Dent. 2001; 14:211-215. [PubMed: 11699739]

14. Van Meerbeek B, Van Landuyt K, De Munck J, Hashimoto M, Peumans M, Lambrechts P, Yoshida Y, Inoue S, Suzuki K. Technique-sensitivity of contemporary adhesives. Dent Mater J. 2005; 24:1-13. [PubMed: 15881200]

15. Misra A, Spencer P, Marangos O, Wang Y, Katz JL. Micromechanical analysis of dentin/adhesive interface by the finite element method. J Biomed Mater Res Part B: Appl Biomater B. 2004; 70:56-65.

16. Misra A, Spencer P, Marangos O, Wang Y, Katz JL. Parametric study of the effect of phase anisotropy on the micromechanical behavior of dentin-adhesive interface. J Roy Soc Interface. 2005; 2:145-157. [PubMed: 16849175]

17. Frankenberger R, Kramer N, Petschelt A. Fatigue behavior of different dentin adhesives. Clin Oral Invest. 1999; 3:11-17.

18. Frankenberger R, Strobel WO, Kramer N, Lohbauer U, Winter-scheidt J, Winterscheidt B, Petschelt A. Evaluation of the fatigue behavior of the resin-dentin bond with the use of different methods. J Biomed Mater Res Part B. 2003; 67:712-721.

19. Staninec M, Kim P, Marshall GW, Ritchie RO, Marshall SJ. Fatigue of dentin-composite interface with four-point bend. Dent Mater. 2008; 24:799-803. [PubMed: 17996931]

20. Park, jG; Ye, Q.; Topp, EM.; Misra, A.; Spencer, P. Water sorption and dynamic mechanical properties of dentin adhesives with a urethane-based multifunctional methacrylate monomer. Dent Mater. 2009; 25:1569-1575. [PubMed: 19709724] 
21. Wineman, AS.; Rajagopal, KR. Mechanical Response of Polymers. Cambridge, UK: Cambridge University Press; 2000.

22. Chen, T. Determining a Prony Series for a Viscoelastic Material from Time Varying Strain Data. U.S Army Research Laboratory; 2000.

23. Dooling PJ, Buckley CP, Hinduja S. An intermediate model method for obtaining a discrete relaxation spectrum from creep data. Rheological Acta. 1997; 36:472-482.

24. Baumgaertel M, Winter HH. Determination of discrete relaxation and retardation time spectra from dynamic mechanical data. Rheological Acta. 1989; 28:511-519.

25. Tschoegl NW, Emri I. Generating line spectra from experimental response. III. Interconversion between relaxation and retardation behavior. Int J Polymerica Mater. 1992; 18:117-127.

26. Park SW, Kim YR. Fitting prony-series viscoelastic models with power-law presmoothing. J Mater Civil Eng. 2001; 13:26-32.

27. Nalla RK, Kinney JH, Marshall SJ, Ritchie RO. On the in vitro fatigue behavior of human dentin: Effect of mean stress. J Dent Res. 2004; 83

28. Myllytie P, Salmen L, Haimi E, Laine J. Viscoelasticity and water plasticization of polymercellulose composite films and paper sheets. Cellulose. 2010; 17:375-385. 


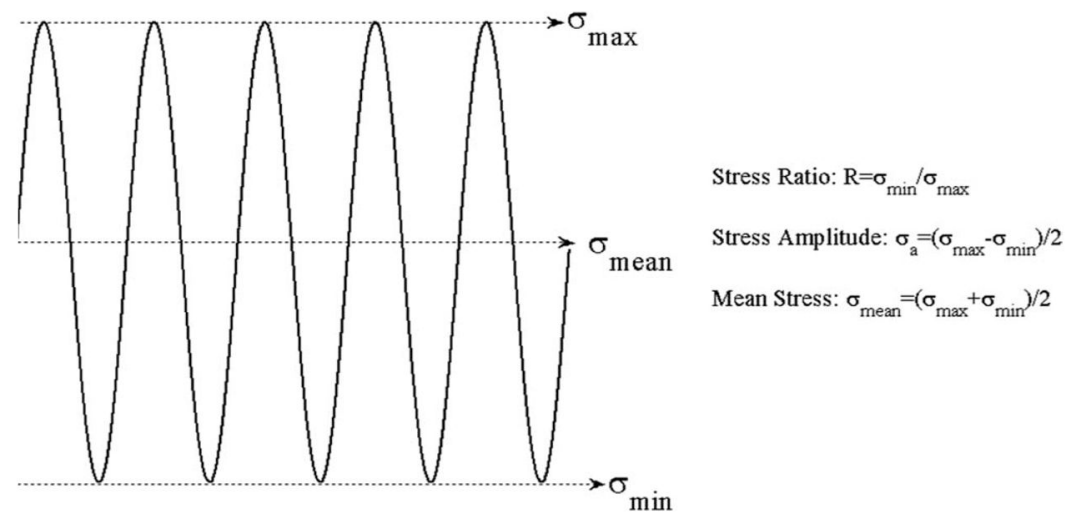

FIGURE 1.

Cyclic loading during fatigue test. 


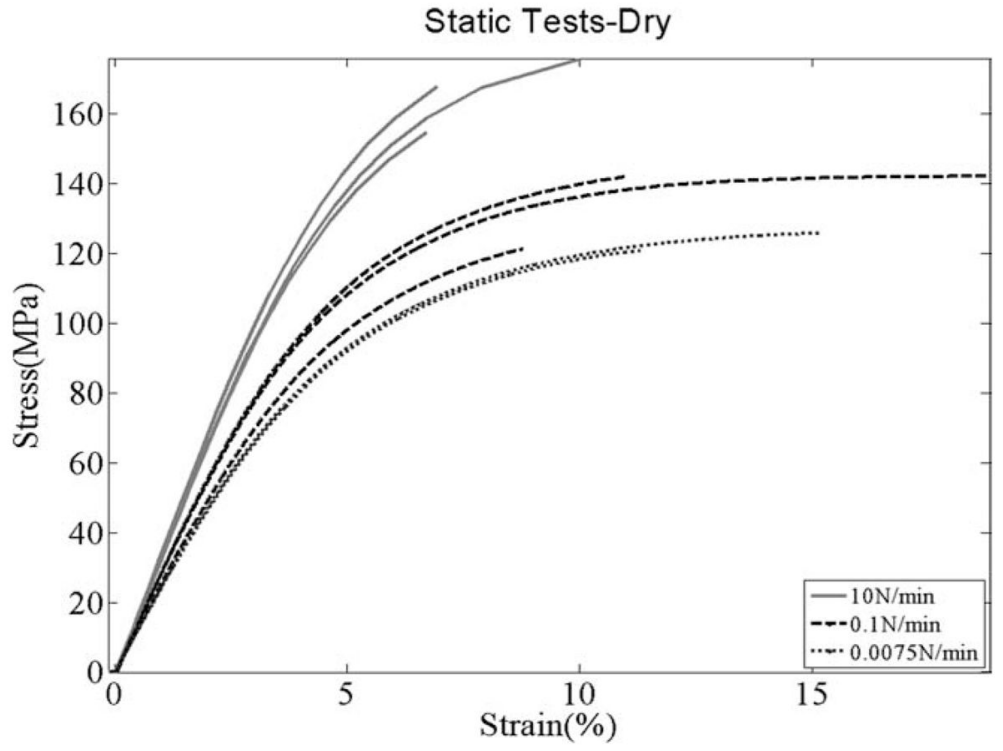

FIGURE 2.

Stress-strain curves at different loading rate in dry conditions. 


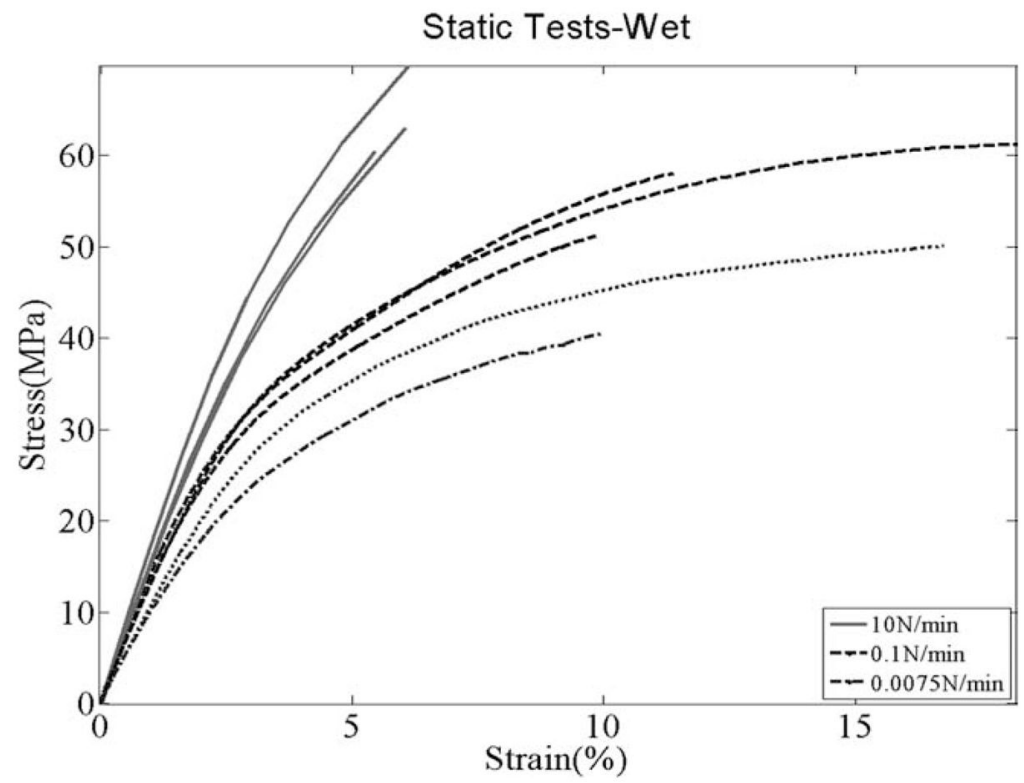

FIGURE 3.

Stress-strain curves at different loading rate in wet conditions. 


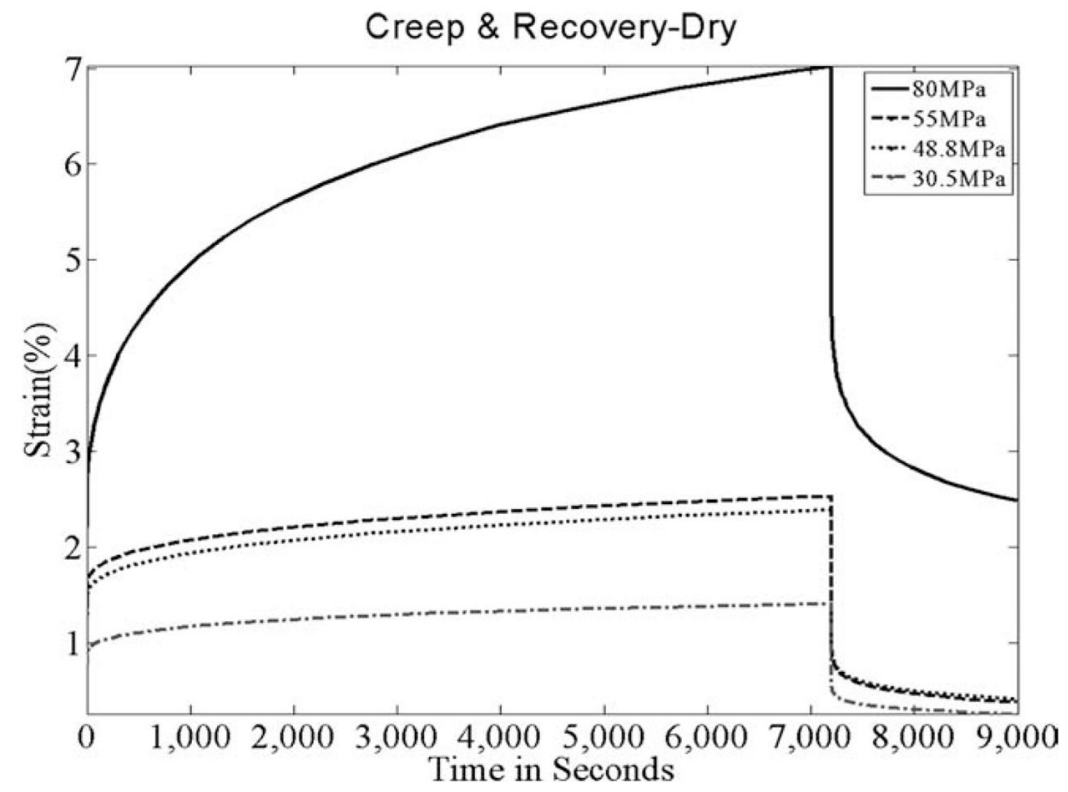

FIGURE 4.

Creep and recovery test at different stress levels in dry conditions. 


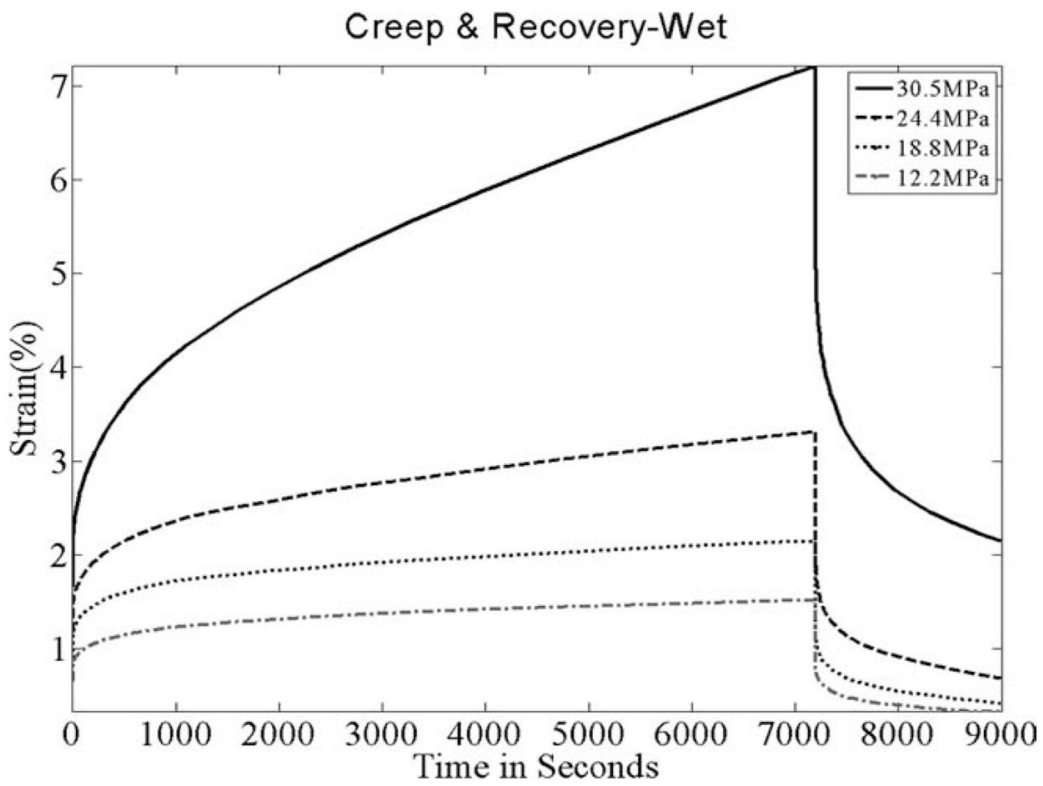

FIGURE 5.

Creep and recovery test at different stress levels in wet conditions. 


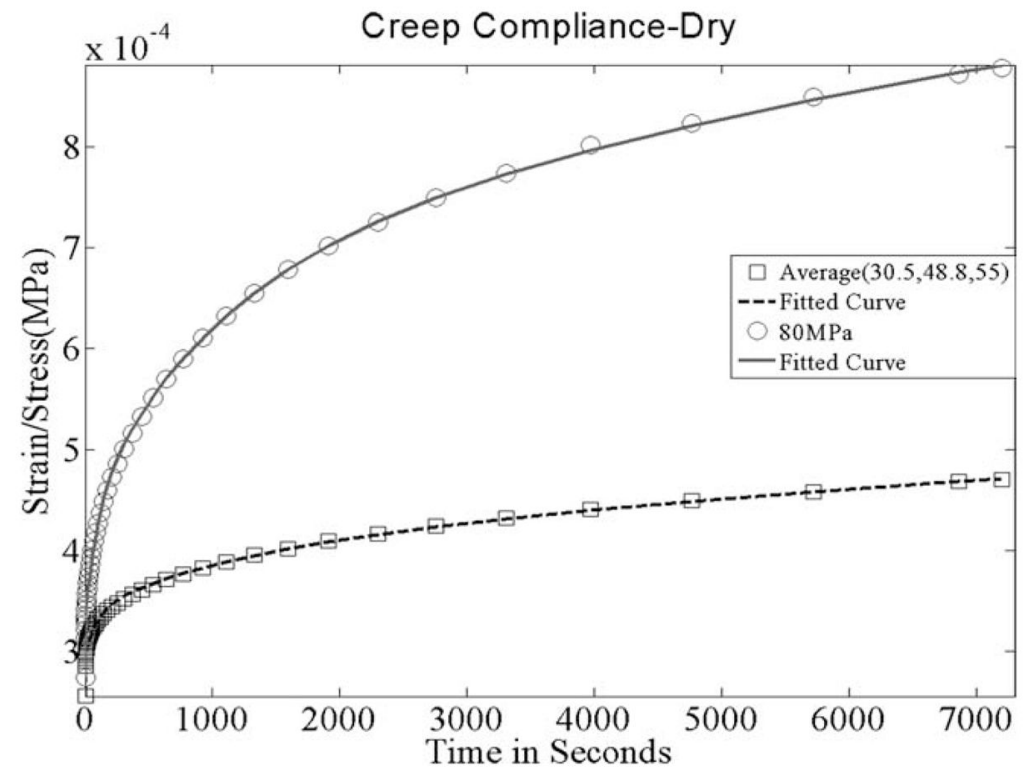

FIGURE 6.

Creep compliance along with fitted curves for dry testing. 


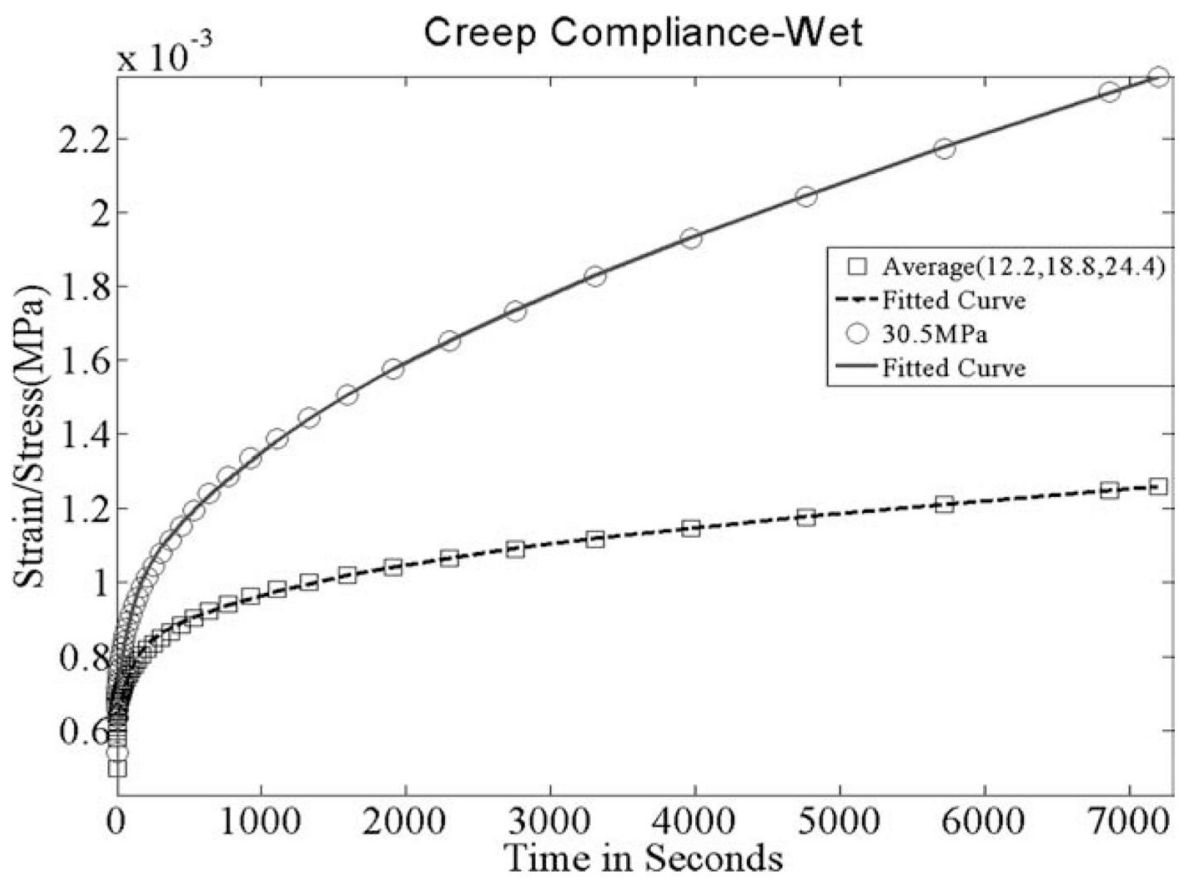

FIGURE 7.

Creep compliance along with fitted curves for wet testing. 


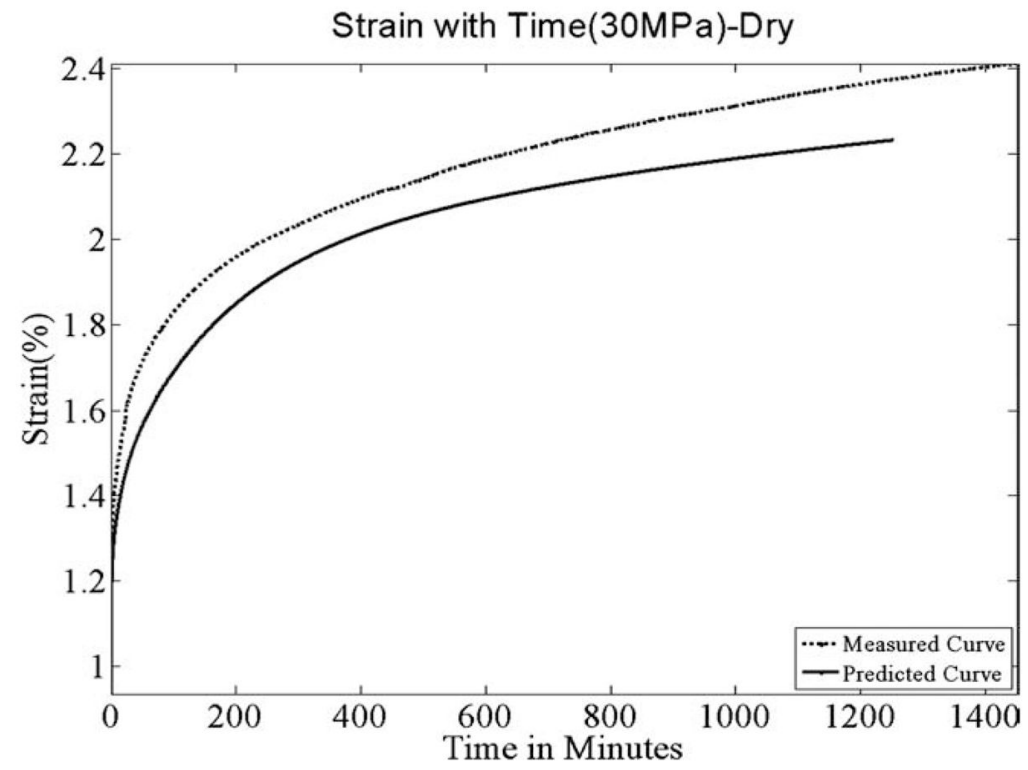

FIGURE 8.

Strain versus time curves-dry testing conditions-30 MPa. 


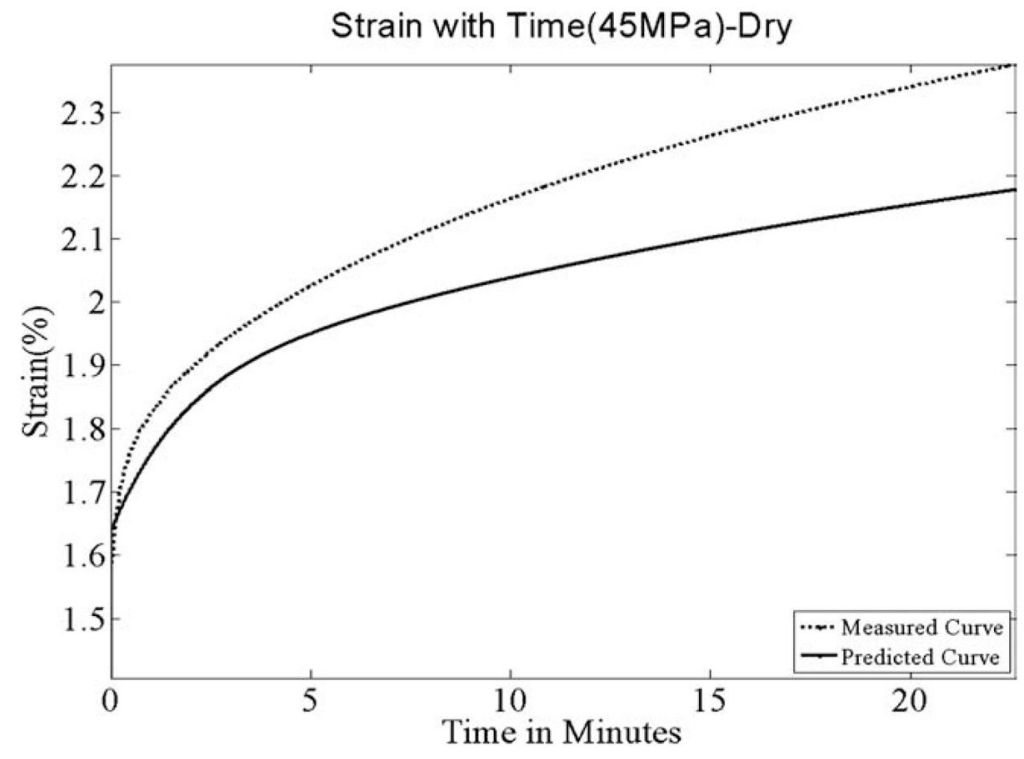

FIGURE 9.

Strain versus time curves-dry testing conditions-45 $\mathrm{MPa}$. 


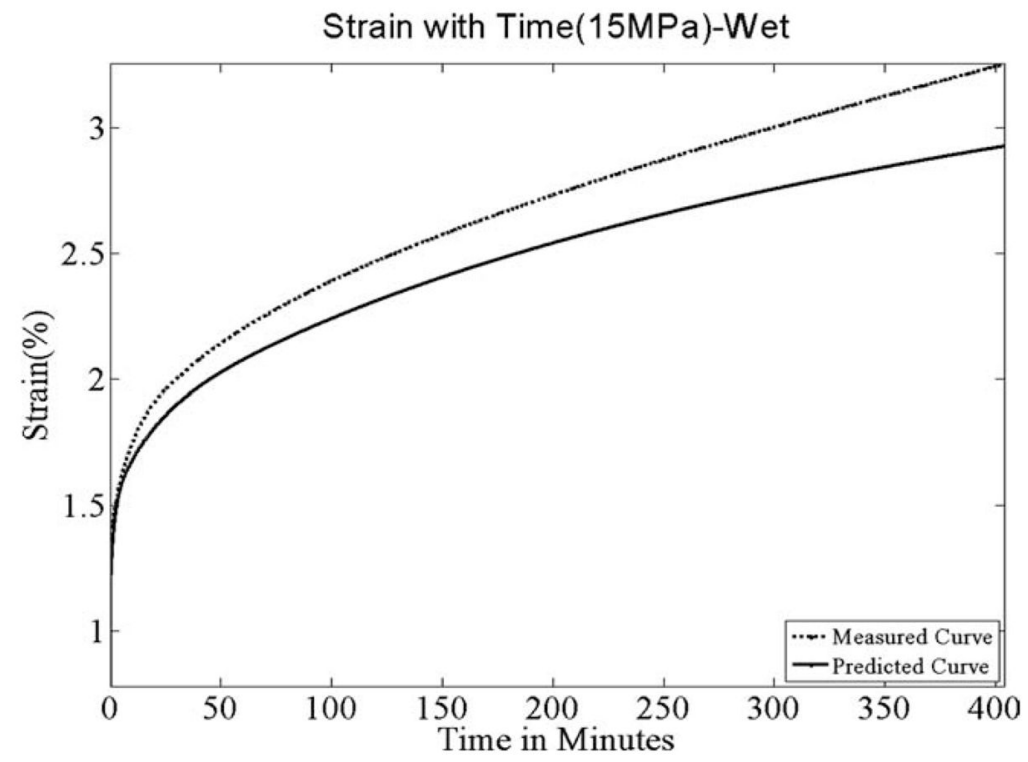

FIGURE 10.

Strain versus time curves-wet testing conditions-15 MPa. 


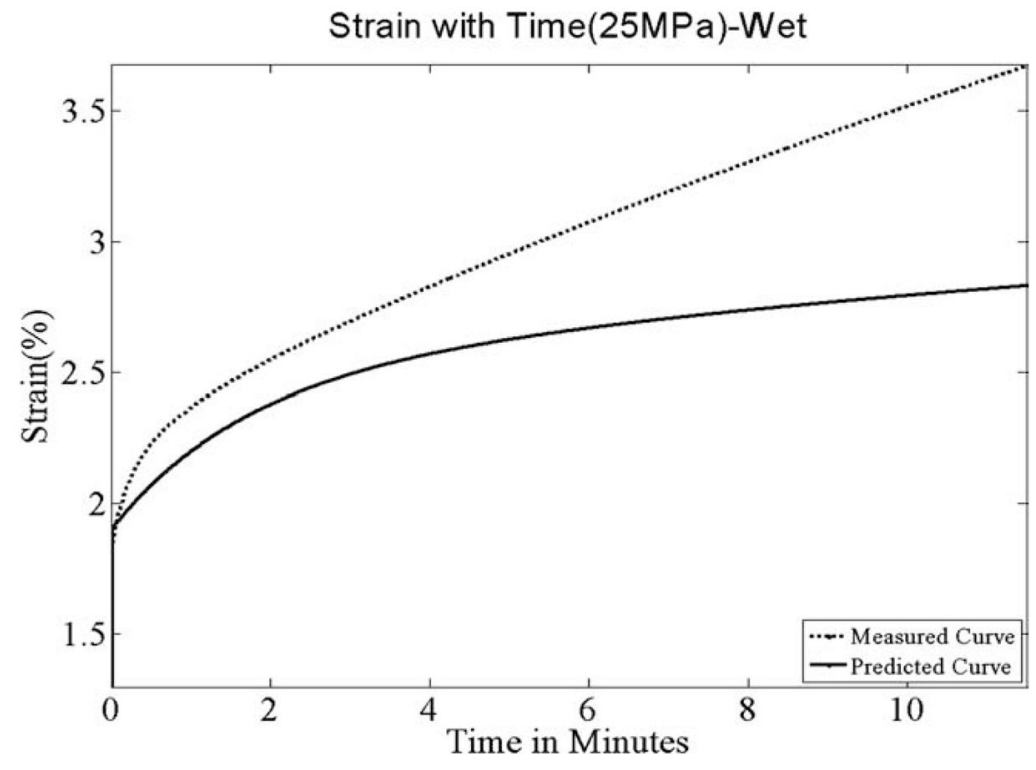

FIGURE 11.

Strain versus time curves-wet testing conditions-25 MPa. 


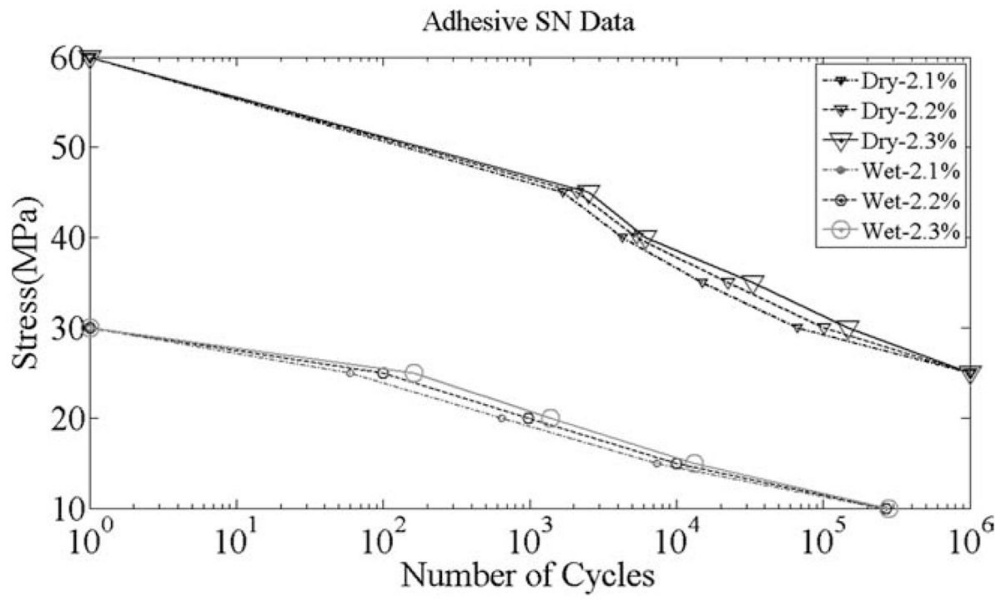

FIGURE 12.

Measured SN data for model dental adhesive in wet and dry conditions. 
TABLE I

Prony Series Parameters for Creep Compliance Function

\begin{tabular}{ccc}
\hline & Dry $\boldsymbol{R}^{\mathbf{2}}=\mathbf{0 . 9 9 5 8}$ & Wet $\boldsymbol{R}^{\mathbf{2}}=\mathbf{0 . 9 9 1 2}$ \\
\hline$J_{0}$ & $2.5510^{-10} \mathrm{~m}^{2} / \mathrm{N}$ & $4.2510^{-10} \mathrm{~m}^{2} / \mathrm{N}$ \\
$J_{1}$ & $4.2010^{-11} \mathrm{~m}^{2} / \mathrm{N}$ & $1.9710^{-10} \mathrm{~m}^{2} / \mathrm{N}$ \\
$J_{2}$ & $4.1610^{-11} \mathrm{~m}^{2} / \mathrm{N}$ & $1.9010^{-10} \mathrm{~m}^{2} / \mathrm{N}$ \\
$J_{3}$ & $4.9610^{-11} \mathrm{~m}^{2} / \mathrm{N}$ & $1.6410^{-10} \mathrm{~m}^{2} / \mathrm{N}$ \\
$J_{4}$ & $1.4110^{-10} \mathrm{~m}^{2} / \mathrm{N}$ & $3.8010^{-10} \mathrm{~m}^{2} / \mathrm{N}$ \\
$J_{5}$ & $1.510^{-10} \mathrm{~m}^{2} / \mathrm{N}$ & $1.2710^{-9} \mathrm{~m}^{2} / \mathrm{N}$ \\
$\tau_{1}$ & $0.1 \mathrm{~s}$ & $0.125 \mathrm{~s}$ \\
$\tau_{2}$ & $100 \mathrm{~s}$ & $100 \mathrm{~s}$ \\
$\tau_{3}$ & $1,000 \mathrm{~s}$ & $1,000 \mathrm{~s}$ \\
$\tau_{4}$ & $10,000 \mathrm{~s}$ & $10,000 \mathrm{~s}$ \\
$\tau_{5}$ & $100,000 \mathrm{~s}$ & $100,000 \mathrm{~s}$ \\
\hline
\end{tabular}


TABLE ॥

Apparent Elastic Modulus in Dry and Wet Conditions

\begin{tabular}{lccccc}
\hline & \multicolumn{2}{c}{ Modulus, GPa (Dry) } & & \multicolumn{2}{c}{ Modulus, GPa (wet) } \\
\cline { 2 - 3 } Loading Rate N/min & Measured & Calculated & & Measured & Calculated \\
\hline $10 \mathrm{~N}$ & 3.53 & 3.34 & & 1.62 & 1.59 \\
$0.1 \mathrm{~N}$ & 3.06 & 2.93 & & 1.46 & 1.33 \\
0.0075 & 2.56 & 2.42 & & 1.04 & 1.08 \\
\hline
\end{tabular}




\section{TABLE III}

Number of Cycle to Failure at Different Stress Amplitude for Dry Testing

\begin{tabular}{lccc}
\hline Stress Amplitude (MPa) & $\begin{array}{c}\text { No of Cycles 2.1\% Strain } \\
\text { Average (std) }\end{array}$ & $\begin{array}{c}\text { No of Cycles 2.2\% Strain } \\
\text { Average (std) }\end{array}$ & $\begin{array}{c}\text { No of Cycles 2.3\% Strain Average } \\
\text { (std) }\end{array}$ \\
\hline 45 & $1,680(402)$ & $2,115(926)$ & $2,530(1,756)$ \\
40 & $4,275(721)$ & $5,380(1,738)$ & $6,130(2,865)$ \\
35 & $15,010(14,233)$ & $22,480(20,967)$ & $33,075(30,284)$ \\
30 & $67,045(54,877)$ & $100,580(85,948)$ & $147,860(130,737)$ \\
\hline
\end{tabular}




\section{TABLE IV}

Number of Cycle to Failure at Different Stress Amplitude for Wet Testing

\begin{tabular}{lccc}
\hline Stress Amplitude (MPa) & $\begin{array}{c}\text { No of Cycles 2.1\% Strain } \\
\text { Average (std) }\end{array}$ & $\begin{array}{c}\text { No of Cycles 2.2\% Strain } \\
\text { Average (std) }\end{array}$ & $\begin{array}{c}\text { No of Cycles 2.3\% Strain } \\
\text { Average (std) }\end{array}$ \\
\hline 25 & $60(20)$ & $100(33)$ & $165(58)$ \\
20 & $645(66)$ & $985(107)$ & $1,385(153)$ \\
15 & $7,390(4,574)$ & $9,995(6,592)$ & $13,205(9033)$ \\
10 & $258,305(216,769)$ & $268,115(202,055)$ & $279,510(185,455)$ \\
\hline
\end{tabular}

